\title{
Value Cluster Assessment Using Game Theory
}

\author{
Chumpol Saichuer ${ }^{1, *}$, Sataporn Amornsawadwatana ${ }^{2}$, Wanchai Rattanawong ${ }^{2}$ \\ ${ }^{1}$ School of Engineering, University of the Thai Chamber of Commerce, Thailand \\ ${ }^{2}$ Department of Logistics Engineering, School of Engineering, University of the Thai Chamber of Commerce, Thailand
}

Copyright $\bigcirc 2016$ by authors, all rights reserved. Authors agree that this article remains permanently open access under the terms of the Creative Commons Attribution License 4.0 International License

\begin{abstract}
Game theory is a study of strategic decision making. To be fully defined, a game must specify the following elements: the players of the game, the information and actions available to each player at each decision point, and the payoffs for each outcome. The payoff matrix represents strategic analytical tool developed and based on the game theory. This research study applied game theory into the value cluster model in logistics service providers to present an overview of previous suggestions regarding the relationship between providers in light of mutual benefit, relationship, and satisfaction. Four different aspects in developing strategic and business perspectives were developed according to zero sum game that comprised of attack, exploit, bargain, and defend that may be considered by several organizations. An exemplary case study of logistics service providers was studied using such four different aspects.
\end{abstract}

Keywords Value Cluster, Game Theory

\section{Introduction}

Game theory is a study of strategic decision making. More formally, it is "the study of mathematical models of conflict and cooperation between intelligent rational decision-makers". An alternative term suggested "as a more descriptive name for the discipline" is interactive decision theory. Game theory is mainly used in economics, political science, and psychology, as well as logic and biology. The subject first addressed zero-sum games, such that one person's gains exactly equal net losses of the other participant(s) Aumann and Shapley (1974) [1].The games studied in game theory are well-defined mathematical objects. To be fully defined, a game must specify the following elements: the players of the game, the information and actions available to each player at each decision point, and the payoffs for each outcome. A game theorist typically uses these elements, along with a solution concept of their choosing, to deduce a set of equilibrium strategies for each player such that, when these strategies are employed, no player can profit by unilaterally deviating from their strategy. These equilibrium strategies determine equilibrium to the game - a stable state in which either one outcome occurs or a set of outcomes occur with known probability. Most cooperative games are presented in the characteristic function form, while the extensive and the normal forms are used to define non-cooperative games Harsanyi (1974) [4].

\section{Applying Game Theory into the Value Cluster Model}

\subsection{Payoff Matrix}

A payoff matrix is a decision analysis tool that summarizes pros and cons of a decision in a tabular form. It lists payoffs (negative or positive returns) associated with all possible combinations of alternative actions (under the decision maker's control) and external conditions (not under decision maker's control) Myerson (1991) [14]. The Payoff matrix is an expression of the first law of decision science. Each row represents one action that the decision maker might or might not freely choose to perform; each column represents a possible state of nature. At the time the decision must be made the decision maker assumes that one of the columns represents the actual decision situation, but her or she does not know which column is the correct one. The cells of the matrix represent payoffs that the decision maker would receive if he or she chose the action represented by a particular row and the actual state of nature were the one represented by a particular column Nash (1950) [9].

\subsection{Payoff Matrix Analysis}

From the payoff matrix shown in Table 1, it represents strategic analytical tool developed and based on the game theory. Using the five force model or other analysis tool was done for analyzing current conditions. This research determined hypotheses used for developing analytical tool, followed by competitive zero sum game. After the elaborate analysis of competitiveness, it was suggested that unmatched service or product made by the case study was used for winning competitors. To attack against the competitors, one may cut a product price down and expand own markets that creates profit. The thesis also focuses on how the business was exploited, and bargained. Bargaining was found to be 
made for conclusions whether or not benefit would be shared according to a game plan. A company may link to its supply chain started from supplier, transportation service provider, warehouse, distributor, wholesaler, and retailer with further make a relationship to a consumer. Such relationship creates closer trust and loyalty in product or service. In addition, a company may also need to improve its operation and strategy that becomes a key role of the company. It was due to the operational department responsible for producing a product and improving a level of service.

Table 1. Analytical Tool in Developing Strategy for Game Theory

\begin{tabular}{|l|l|}
\hline \multicolumn{1}{|c|}{ Attack } & \multicolumn{1}{|c|}{ Exploit } \\
- In-depth competitive analysis & - Sales growth \\
- Product leadership & - Cost leadership \\
\hline \multicolumn{1}{|c|}{ Bargain } & \multicolumn{1}{|c|}{ Defend } \\
- Customer relationship & - Best practice of operations \\
- Linking supply chain among & - Efficiency and productivity \\
vendors & improvement \\
\hline
\end{tabular}

Therefore, the company may need to consider every aspects of efficiency such as sale, marketing, production, delivery, or customer service, etc. This research study summarized and raised important questions from 4 different aspects in developing strategic and business perspectives.

- The competitor finds every ways to increase market segmentation; thereby every way to attack and take action should be made violently.

- Any incoming opportunities or ways to draw customers from the competitor should be taken; thereby how demands can be exploited.

- Low cost leadership can be used for making the highest profit; thereby the competitor and customer may fairly bargain and share their benefit.

- Invading and attacking done by the competitor can draw customers out of an overall market share; thereby defense should be reflected to protect own company and leave from unexpected catastrophic.
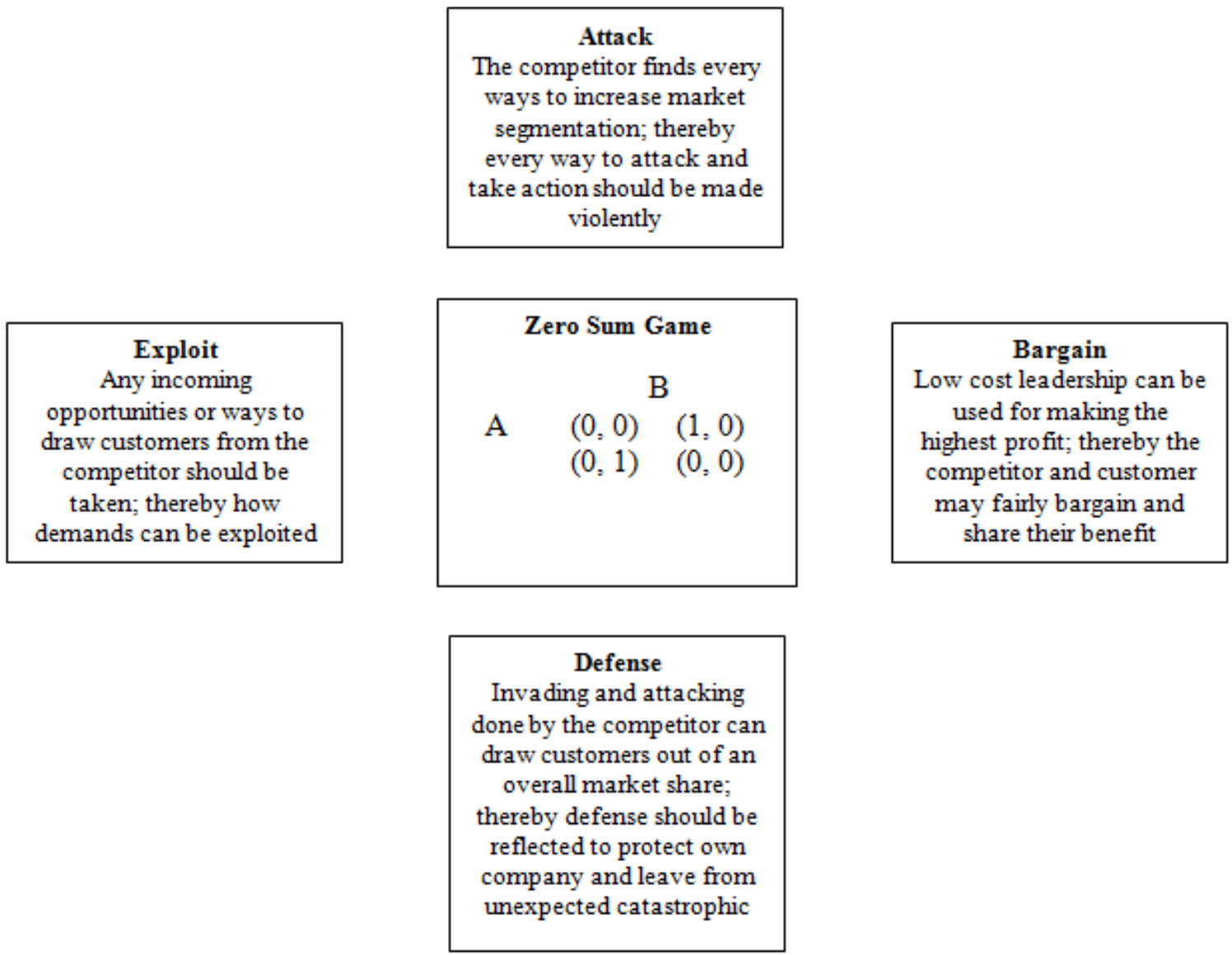

Figure 1. Analytical Tool in Developing Strategy for Game Theory with Zero Sum Game 
Figure 1 illustrates how to use the analytical tool with four developing strategies for game theory consideration according to zero sum game. These four strategies comprise of attack, exploit, bargain, and defense that may be considered by several organizations. For the first question, attacking against the competitors need inducement and motivation in order to quickly respond. For example, describing the business competition perspective may be relevant to market segmentation of other competitors that generate less profit. Therefore, the company should strategically respond to remove its competitors from the compete market. Whereas, allowing another allied company to attack against such competitors. The more both parties rigorously attack against each other, the worsen reputation may also develop, resulting in the exemplary company to gain positivity of reputation or promote negative insult to each other. This may result in the better and positive look from their customers towards the company's reputation. Even, destroying its counterpart may need other hands to attack against the competitors without thinking on ethics or norms to win circumstances. To destroy the competitors need any methods to accomplish the goal, or even to make up something that creates illegitimate practice towards other competitors. Once, the competitors feel comfortable on the strike back then they may incorporate with other alliances to make a competition. Another situation is when the company entirely losses due to several reasons, then every way possible to overcome the problems is a must. Applying such concept to the game theory can represent in form of payoff matrix illustrated in Table 2 .

Table 2. Payoff Matrix for Attack

\begin{tabular}{|c|c|c|c|}
\hline \multirow{4}{*}{ A } & \multicolumn{3}{|c|}{ B } \\
\cline { 2 - 4 } & & Not Attack & Attack \\
\cline { 2 - 4 } & Not Attack & $(0,0)$ & $(0,1)$ \\
\cline { 2 - 4 } & Attack & $(1,0)$ & $(0,0)$ \\
\hline
\end{tabular}

Table 3. Payoff Matrix for Exploit

\begin{tabular}{|c|c|c|c|}
\hline \multirow{4}{*}{ A } & \multicolumn{3}{|c|}{ B } \\
\cline { 2 - 4 } & & Not Exploit & Exploit \\
\cline { 2 - 4 } & Not Exploit & $(0,0)$ & $(0,1)$ \\
\cline { 2 - 4 } & Exploit & $(1,0)$ & $(0,0)$ \\
\hline
\end{tabular}

The second question detailing how does the company identify a group of previous or new customers being interested in that particular product. The company may need to develop strategy in drawing this customers' group to exploit from a segmentation of overall markets. Even if a high risk may be raised due to negative comments from its competitors or stress that is caused by surrounding pressures. Taking opportunity or finding other channels is not only accomplished by a marketing department, but also a sale and customer service department. Finding customers involves with meeting them done by the sale and customer and service department. Normally, several companies allow the marketing department to directly deal with those customers. Considering competitors or other parties, they also attempt to identify any marketing channels. Therefore, knowing a progress of the competitors may strategically succeed the way in which marketing segment is expanded. This can be applied to the payoff matrix for exploitation of other competitors illustrated in Table 3.

For the third question, any companies should carefully consider how to negotiate or bargain depending on each and every circumstance. Each party has its own limit that is not seen by another, resulting in unknown limit seen by each other. When each party does not know their true limit in a bargaining process, then they will find the way to predict the counterpart's capability or limit. Both parties may bargain to negotiate whether which one is right or wrong, however, bargaining should be compromised without positive force resulting in accomplishment. When bargaining reaching a negotiation between two parties, both can fairly satisfy with the ultimate results. Using an unneeded force will make no difference to enhance the bargaining power. Without this force against each party, accomplishment may be occurred. The bargaining practice can be reached by each party accepts some point that is appreciated. It becomes a fair treatment between both parties; even if they may not ethical accept the outcome. The bargaining practice is thought to be involved with seeking mutual benefit. Satisfaction on the benefit will lead to fair treatment and can be illustrated in Table 4 .

Table 4. Payoff Matrix for Bargain

\begin{tabular}{|c|c|c|c|}
\hline \multirow{4}{*}{$\mathrm{A}$} & \multicolumn{3}{|c|}{ B } \\
\cline { 2 - 4 } & & Not Bargain & Bargain \\
\cline { 2 - 4 } & Not Bargain & $(0,0)$ & $(0,1)$ \\
\cline { 2 - 4 } & Bargain & $(1,0)$ & $(0,0)$ \\
\hline
\end{tabular}

Every issue raised by any companies is related to how to defend itself from being attacked, and may not attack competitors in any situation. These competitors may be not defeated in a way that defense against them leveling from the least to the most. Thereby, preparing for the defenses may need to consider and make a decision that to what degree it should be and to what level of defending to the competitors should be identified and preventing them from attacking. Strategic defense can be done by stepping back, and finding opportunity to deal with the competitors to lessen its capacity. A barrier between both parties needs to be shattered firstly; doing so results in creating more space in one party's area. This may allow to strategically attacking a counterpart. Table 5 illustrates a payoff matrix for defense.

Table 5. Payoff Matrix for Defense

\begin{tabular}{|c|c|c|c|}
\hline \multirow{4}{*}{$\mathrm{A}$} & \multicolumn{3}{|c|}{ B } \\
\cline { 2 - 4 } & & Not Defense & Defense \\
\cline { 2 - 4 } & Not Defense & $(0,0)$ & $(0,1)$ \\
\cline { 2 - 4 } & Defense & $(1,0)$ & $(0,0)$ \\
\hline
\end{tabular}

After assuming the hypothesis of the analytical framework, this research study applied this concept to be used with an exemplary case study. The rationale behind was that the analytical tool might be applicable for logistics service providers, in accompany with strategic development of game theory. 


\subsection{Exemplary Case Study of Transportation Service Providers}

This exemplary case study was conducted as easier and comprehensible as possible to develop strategy, using the case study of a group of transportation service providers nearby Bangkok area. The reason behind was that there were a number of service providers competing each other that seems to be akin to game competing. Normally, those transportation groups provided its service to several factories, imports/exports, or other related services in both domestic and international markets.

Thereby, the case study may need to adjust strategy that suits for exploiting market segmentation. The company ran its transportation business due to high demand, and few business competitors. Even though, several companies existed in competitive market lower the cost of goods sold. The following section illustrates how in-depth interview was conducted along with primary data collected using a questionnaire. Also, the secondary data was collected by using annual report, balance sheet, income statement, sale and marketing report. After both data type was collected, it was further analyzed in reference to the aforementioned conceptual framework and analytical tools.

From Figure 3 illustrates the payoff matrix used for competition between transportation service provider group (A) and its competitor B. It was found that business competitiveness of $\mathrm{A}$ was better than $\mathrm{B}(1,0)$, as $\mathrm{A}$ represents 1 and B represents 0 with several strategic factors such as operational best practice, customer relationship, product leadership, sale volume growth, increasing efficiency and output, linkage between vendors in supply chain, or cost leadership. 1 represents win that is $\mathrm{A}$, and 0 represents loss that is $\mathrm{B}$. In some situations, $\mathrm{B}$ might compete with $\mathrm{A}(0,1)$ due to the use of the following strategic factors: operational best practice, customer relationship, sale volume growth, increasing efficiency and output, linkage between vendors in supply chain, or cost leadership. Vice versa, 1 represents win that is $\mathrm{B}$, and 0 represents loss that is $\mathrm{A}$.

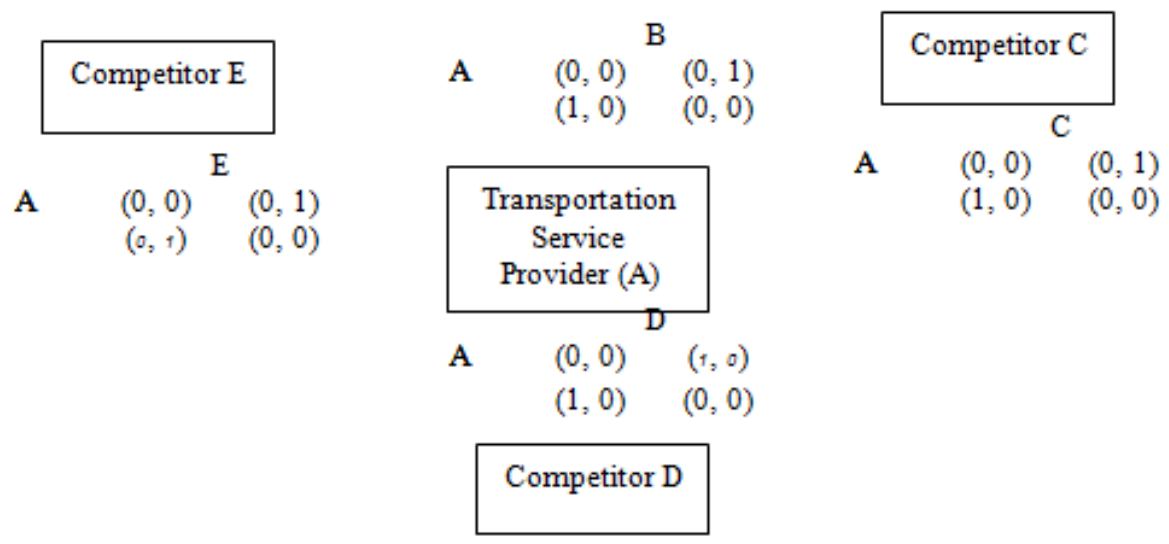

Figure 2. Payoff Matrix for Competition between Transportation Service Provider and Other Competitors

Transportation Service Providers Group and Its Competitor B

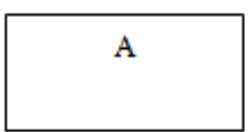

Strategic Factor

-Operational Best Practice

-Customer Relationship

-Product Leadership

-Sale Volume Growth

-Increasing Efficiency and Output

-Linkage between Vendors in

Supply Chain

-Cost Leadership
A
$(0,0)$
$(0,1)$
$(1,0) \quad(0,0)$

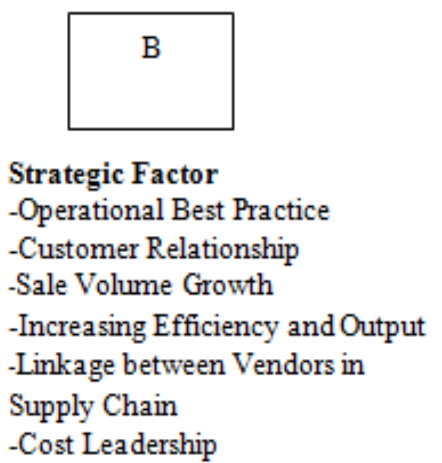

Strategic Factor

-Operational Best Practice

mer Relationship

-Increasing Efficiency and Output

Supply Chain

-Cost Leadership

Figure 3. Payoff Matrix for Competition between Transportation Service Provider Group (A) and Competitor B

The below table illustrates how to apply to a numerous games or strategies related to the game theory. 


\begin{tabular}{|c|c|c|c|}
\hline \multicolumn{2}{|c|}{} & \multicolumn{2}{|c|}{ B } \\
\hline \multirow{2}{|c|}{} & High Pricing & Low Pricing \\
\hline \multirow{3}{*}{ A } & $\begin{array}{c}\text { High } \\
\text { Pricing }\end{array}$ & $(\mathbf{2 5}, \mathbf{2 1})$ & $(\mathbf{2 3 , 1 9 )}$ \\
\cline { 2 - 4 } & Low Pricing & $(\mathbf{1 8}, \mathbf{2 0})$ & $(\mathbf{1 5}, \mathbf{1 7 )}$ \\
\hline
\end{tabular}

It was illustrated that A and B could determine low or high pricing in which the low pricing found to be dominant strategy. Nevertheless, A was able to sell in a number of quantities with saving the best benefit. When B was prone to offer high pricing, it might cause A to determine high pricing that leads to higher benefit compared to low pricing (25 Vs. 18). In the meantime, $\mathrm{B}$ was prone to offer low pricing causing A to determine high pricing that leads to higher benefit compared to low pricing (23 Vs. 15). Therefore, determining low pricing of A was found to be the dominant strategy.

\section{Transportation Service Providers Group and Its Competitor C}

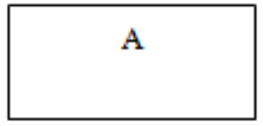

Strategic Factor

-Operational Best Practice

-Customer Relationship

-Product Leadership

-Sale Volume Growth

-Increasing Efficiency and Output

-Linkage between Vendors in

Supply Chain

-Cost Leadership

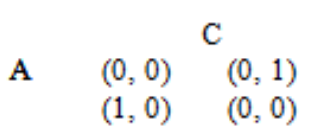

$(0,1)$

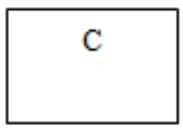

Strategic Factor

-Operational Best Practice

-Customer Relationship

-Sale Volume Growth

-Increasing Efficiency and Output

-Linkage between Vendors in

Supply Chain

-Cost Leadership

Figure 4. Payoff Matrix for Competition between Transportation Service Provider Group (A) and Competitor C

From Figure 4 illustrates the payoff matrix used for competition between transportation service provider group (A) and its competitor C. It was found that business competitiveness of $\mathrm{A}$ was better than $\mathrm{C}(1,0)$, as $\mathrm{A}$ represents 1 and $\mathrm{C}$ represents 0 with several strategic factors such as operational best practice, customer relationship, product leadership, sale volume growth, increasing efficiency and output, linkage between vendors in supply chain, or cost leadership. 1 represents win that is A, and 0 represents loss that is $\mathrm{C}$. In some situations, $\mathrm{C}$ might compete with $\mathrm{A}(0,1)$ due to the use of the following strategic factors: operational best practice, customer relationship, sale volume growth, increasing efficiency and output, linkage between vendors in supply chain, or cost leadership. Vice versa, 1 represents win that is $\mathrm{C}$, and 0 represents loss that is $\mathrm{A}$.

The below table illustrates how to apply to a numerous games or strategies related to the game theory.

\begin{tabular}{|c|c|c|c|}
\hline \multicolumn{2}{|c|}{} & \multicolumn{2}{|c|}{ C } \\
\hline \multirow{2}{|c|}{} & High Pricing & Low Pricing \\
\hline \multirow{3}{*}{ A } & $\begin{array}{c}\text { High } \\
\text { Pricing }\end{array}$ & $(\mathbf{2 5}, \mathbf{2 3})$ & $(\mathbf{2 3}, \mathbf{1 1})$ \\
\cline { 2 - 4 } & Low Pricing & $(\mathbf{1 8}, \mathbf{2 2})$ & $(\mathbf{1 6}, \mathbf{2 0})$ \\
\hline
\end{tabular}

It was illustrated that $\mathrm{A}$ and $\mathrm{C}$ could determine low or high pricing in which the low pricing found to be dominant strategy. Nevertheless, A was able to sell in a number of quantities with saving the best benefit. When $\mathrm{C}$ was prone to offer high pricing, it might cause A to determine high pricing that leads to higher benefit compared to low pricing (18 Vs. $25)$. In the meantime, $\mathrm{C}$ was prone to offer low pricing causing A to determine high pricing that leads to higher benefit compared to low pricing (16 Vs. 23). Therefore, determining low pricing of $\mathrm{A}$ was found to be the dominant strategy.

From Figure 5 illustrates the payoff matrix used for competition between transportation service provider group (A) and its competitor D. It was found that business competitiveness of A was better than $\mathrm{D}(1,0)$, as $\mathrm{A}$ represents 1 and $C$ represents 0 with several strategic factors such as operational best practice, customer relationship, product leadership, sale volume growth, increasing efficiency and output, linkage between vendors in supply chain, or cost leadership. 1 represents win that is A, and 0 represents loss that is D. In some situations, D might compete with $\mathrm{A}(0,1)$ due to the use of the following strategic factors: operational best practice, customer relationship, sale volume growth, increasing efficiency and output, linkage between vendors in supply chain, or cost leadership. Vice versa, 1 represents win that is D, and 0 represents loss that is $\mathrm{A}$. 


\section{Transportation Service Providers Group and Its Competitor D}

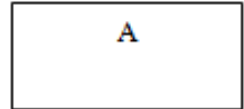

Strategic Factor

-Operational Best Practice

-Customer Relationship

-Product Leadership

-Sale Volume Growth

-Increasing Efficiency and Output

-Linkage between Vendors in

Supply Chain

-Cost Leadership
$\mathrm{D}$

A

$$
\begin{array}{ll}
(0,0) & (0,1) \\
(1,0) & (0,0)
\end{array}
$$

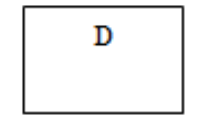

Strategic Factor

-Operational Best Practice

-Customer Relationship

-Sale Volume Growth

-Increasing Efficiency and Output

-Linkage between Vendors in

Supply Chain

-Cost Leadership

Figure 5. Payoff Matrix for Competition between Transportation Service Provider Group (A) and Competitor D

The below table illustrates how to apply to a numerous games or strategies related to the game theory.

\begin{tabular}{|c|c|c|c|}
\hline \multicolumn{2}{|c|}{} & \multicolumn{2}{|c|}{ D } \\
\hline \multirow{2}{*}{ A } & High Pricing & Low Pricing \\
\cline { 2 - 4 } & How Pricing & $(25,25)$ & $(30,20)$ \\
\cline { 2 - 4 } & Lowing & $(20,30)$ & $(23,23)$ \\
\hline
\end{tabular}

It was illustrated that $\mathrm{A}$ and $\mathrm{D}$ could determine low or high pricing in which both companies fell into a condition of defendant as the prisoner's dilemma game. Due to both companies were able to offer as high pricing as 25 baht per piece. If two companies preferred to set up high pricing, both would offer low pricing at 23 baht per piece. Nevertheless, it was unsure that which one would set up which pricing leading to another would set up low pricing as exited. In which case, an opponent (D) would offer low pricing at 20 baht per piece but A had to set up low pricing at 30 baht per piece that was found to be higher. This might cause frustration in its competitors; thereby both companies fell into the prisoner's dilemma game. When setting up low pricing would not functional in a long run, but their customers might benefit from purchasing lost cost of products.

\section{$\underline{\text { Transportation Service Providers Group and Its Competitor E }}$}

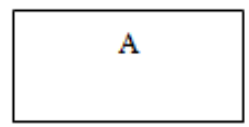

Strategic Factor

-Operational Best Practice

-Customer Relationship

-Product Leadership

-Sale Volume Growth

-Increasing Efficiency and Output

-Linkage between Vendors in

Supply Chain

-Cost Leadership

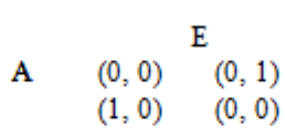

$(0,1)$

$(0,0)$
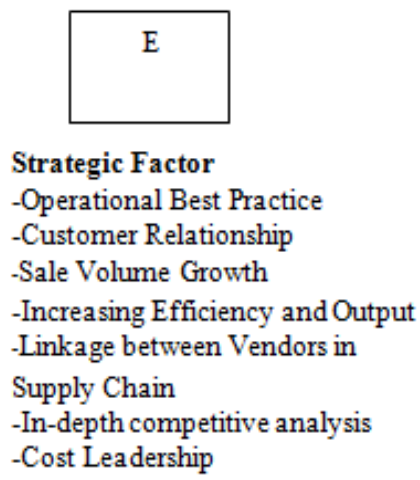

Figure 6. Payoff Matrix for Competition between Transportation Service Provider Group (A) and Competitor E

From Figure 6 illustrates the payoff matrix used for competition between transportation service provider group (A) and its competitor E. It was found that business competitiveness of $\mathrm{E}$ was better than $\mathrm{A}(1,0)$, as $\mathrm{E}$ represents 0 and $\mathrm{A}$ represents 0 with several strategic factors such as operational best practice, customer relationship, product leadership, sale volume growth, increasing efficiency and output, linkage between vendors in supply chain, in-depth competitive analysis, or cost leadership. 1 represents win that is $\mathrm{E}$, and 0 represents loss that is $\mathrm{A}$.

The below table illustrates how to apply to a numerous games or strategies related to the game theory.

\begin{tabular}{|c|c|c|c|}
\hline \multicolumn{2}{|c|}{} & \multicolumn{2}{|c|}{ E } \\
\hline \multicolumn{2}{|c|}{} & High Pricing & Low Pricing \\
\hline \multirow{2}{*}{ A } & High Pricing & $(25,25)$ & $(10,15)$ \\
\cline { 2 - 4 } & Low Pricing & $(15,10)$ & $(15,15)$ \\
\hline
\end{tabular}


It was illustrated that $\mathrm{A}$ and $\mathrm{E}$ could determine low or high pricing in which Nash equilibrium was settled at $(25,25)$ and $(15,15)$. Both points were at the end of the game for both companies. Even if both companies wanted to end the game at $(15,15)$, rather than $(25,25)$ due to low pricing could be afforded by customer purchases. Both points that allow high rewarding were the end of the stag hunt game, requiring coordination of both companies. When E requested to set up low pricing at 25 baht per piece, everyone might signal to offer low pricing of 15 baht and would not know what will happen. One A set up low pricing of 10 baht that generated loss, whereas $\mathrm{E}$ would only benefit a little. As a result, both companies might change their mind to benefit a little as well because the better choice of rewarding of 15 was better than 10. After that, the situation was back to normal at $(15,15)$ thereby both companies returned to offer existing pricing.

Table 6. Value Cluster Analysis Using Game Theory for Transportation Service Provider Group (A)

\begin{tabular}{|c|c|}
\hline \begin{tabular}{l}
\multicolumn{1}{c}{ Attack } \\
- No attack due to receiving an \\
order as Make to Order from \\
overseas customers
\end{tabular} & $\begin{array}{l}\text { Exploit } \\
\text { - Plan to exploit market } \\
\text { segmentation for transportation }\end{array}$ \\
\hline $\begin{array}{l}\text { Bargain } \\
\text {-Bargain with customers with } \\
\text { value adding in products that } \\
\text { allow easier bargaining }\end{array}$ & $\begin{array}{l}\qquad \text { Defense } \\
\text {-No defense from competitors due } \\
\text { to a long contract signed for } \\
\text { production }\end{array}$ \\
\hline
\end{tabular}

Table 7. Value Cluster Analysis Using Game Theory for Competitor B

\begin{tabular}{|c|c|}
\hline \begin{tabular}{l}
\multicolumn{1}{c}{ Attack } \\
-Plan strategy to attach to exploit \\
market segmentation
\end{tabular} & \begin{tabular}{l}
\multicolumn{1}{c}{ Exploit } \\
-Market segmentation for \\
overseas customers
\end{tabular} \\
\hline $\begin{array}{l}\text { Bargain } \\
\text {-Allow both domestic and } \\
\text { international vendors to become } \\
\text { part of business }\end{array}$ & $\begin{array}{l}\quad \text { Defense } \\
\text {-New target especially for US } \\
\text { customers }\end{array}$ \\
\hline
\end{tabular}

Table 8. Value Cluster Analysis Using Game Theory for Competitor C

\begin{tabular}{|c|c|}
\hline \begin{tabular}{l}
\multicolumn{1}{c}{ Attack } \\
-Attack to exploit domestic \\
market segmentation
\end{tabular} & \begin{tabular}{l}
\multicolumn{1}{c}{ Exploit } \\
-Market segmentation for \\
overseas customers
\end{tabular} \\
\hline \begin{tabular}{l}
\multicolumn{1}{c}{ Bargain } \\
-Allow both domestic and \\
international vendors to become \\
part of business
\end{tabular} & $\begin{array}{l}\text { Defense } \\
\text {-Plan for defense in both domestic } \\
\text { and international competitors }\end{array}$ \\
\hline
\end{tabular}

Table 9. Value Cluster Analysis Using Game Theory for Competitor D

\begin{tabular}{|c|c|}
\hline $\begin{array}{c}|c| \\
\text { Attack } \\
\text {-Attack to exploit domestic } \\
\text { market segmentation }\end{array}$ & $\begin{array}{l}\text { Exploit } \\
\text {-Promotion through every medias } \\
\text { to exploit market segmentation }\end{array}$ \\
\hline $\begin{array}{l}\text { Bargain } \\
\text {-Bargain with customers with low } \\
\text { pricing }\end{array}$ & $\begin{array}{l}\text { Defense } \\
\text {-Defense for future market } \\
\text { segmentation }\end{array}$ \\
\hline
\end{tabular}

Table 10. Value Cluster Analysis Using Game Theory for Competitor E

\begin{tabular}{|c|c|}
\hline $\begin{array}{c}\text { Attack } \\
\text {-Attack in individual case }\end{array}$ & $\begin{array}{c}\text { Exploit } \\
\text {-Strategy changed in every } \\
\text { sectors to draw customers }\end{array}$ \\
\hline $\begin{array}{c}\text { Bargain } \\
\text {-Bargain to organization's } \\
\text { customers in individual case }\end{array}$ & $\begin{array}{l}\text { Defense } \\
\text {-Search for new target of high } \\
\text { end customers for value added }\end{array}$ \\
\hline
\end{tabular}

\section{Discussion}

This research study investigated value cluster by using game theory. It applied game theory into the value cluster model in logistics service providers to present an overview of previous suggestions regarding the relationship between providers in light of mutual benefit, relationship, and satisfaction. Strategic and business perspectives were developed using game theory such as dominant strategy, Nash equilibrium, and prisoner's dilemma. The game comprised of attack, exploit, bargain, and defend that may be considered by several companies. This research study raised important questions from 4 different aspects in developing strategic and business perspectives. Firstly, the competitor finds every ways to increase market segmentation; thereby every way to attack and take action should be made violently. Secondly, any incoming opportunities or ways to draw customers from the competitor should be taken; thereby how demands can be exploited. Thirdly, low cost leadership can be used for making the highest profit; thereby the competitor and customer may fairly bargain and share their benefit. Finally, invading and attacking done by the competitor can draw customers out of an overall market share; thereby defense should be reflected to protect own company and leave from unexpected catastrophic. The results were summarized that: 1) A and B could determine low or high pricing in which the low pricing found to be dominant strategy, 2) A and C could determine low or high pricing in which the low pricing found to be dominant strategy, 3) A and $\mathrm{D}$ could determine low or high pricing in which both companies fell into a condition of defendant as the prisoner's dilemma game, and 4) A and E could determine low or high pricing in which nash equilibrium. Value cluster model has identified using game theory to differentiate from one to another, and allowed one company to select its strategy to accommodate with other competitors.

\section{REFERENCES}

[1] Aumann, R.J. and Shapley, L.S. (1974), Values of Non-Atomic Games, Princeton University Press.

[2] Bardi, Edward; John Coyle and Robert Novack (2006). Management of Transportation. Thomson South-Western. ISBN 0-324-31443.

[3] David Blanchard (2010), Supply Chain Management Best Practices, 2nd. Edition, John Wiley \& Sons, ISBN 9780470531884.

[4] Harsanyi, John C. (1974), "An equilibrium point interpretation of stable sets", Management Science 20 (11): 1472-1495, doi:10.1287/mnsc.20.11.1472.

[5] Luce, R. Duncan; Raiffa, Howard (1957), Games and decisions: introduction and critical survey, New York: Wiley. 
[6] Martin Shubik (1981). "Game Theory Models and Methods in Political Economy," in Handbook of Mathematical Economics, v. 1, pp. 285-330.

[7] Martin Shubik (1978). "Game Theory: Economic Applications," in W. Kruskal and J. M. Tanur, ed., International Encyclopedia of Statistics, v. 2, pp. 372-78.

[8] Maynard Smith, John (1982), Evolution and the theory of games, Cambridge University Press, ISBN 978-0-521-28884-2.

[9] Nash, John (1950), "Equilibrium points in n-person games", Proceedings of the National Academy of Sciences of the United States of America 36 (1), pp. 48-49.

[10] Noam Nisan et al., ed. (2007). Algorithmic Game Theory, Cambridge University Press.

[11] Psychological Pricing in Mergers \& Acquisitions using Game Theory by N. Agarwal and P. Zeephongsekul, School of Mathematics and Geospatial Sciences, RMIT University, Melbourne

[12] R. Aumann and S. Hart, ed., 1994. Handbook of Game Theory with Economic Applications, v. 2, outline links, ch. 30:
"Voting Procedures" \& Ch. 31: "Social Choice."

[13] R. J. Aumann ([1987, 2008]). Game theory, Introduction, The New Palgrave Dictionary of Economics, 2nd Edition. Abstract.

[14] Roger B. Myerson (1991). Game Theory: Analysis of Conflict, Harvard University Press, p. 1. Chapter-preview links, pp. vii-xi.

[15] Shapley, L. S. (1953), Stochastic Games, Proceedings of National Academy of Science Vol. 39, pp. 1095-1100.

[16] Ventac Partners (2011). Value from cluster formation, [Online Available]: http://www.ventac-partners.com/biotech_cluster _development.html.

[17] von Neumann, John (1928), "Zur Theorie der Gesellschaftsspiele", Mathematische Annalen 100 (1): p. 295-320. English translation: "On the Theory of Games of Strategy," in A. W. Tucker and R. D. Luce, ed. (1959), Contributions to the Theory of Games, v. 4, p p. 13-42, Princeton University Press.

[18] Von Neumann, John; Morgenstern, Oskar (1944), Theory of games and economic behavior, Princeton University Press. 